\title{
Новый способ открытой репозиции и удержания костных отломков с использованием пластиковых хомутов-стяжек
}

\author{
П.А. Иванов, А.В. Касацкий, Н.Н. Заднепровский, \\ А.Н. Неведров \\ ГБУЗ «Научно-исследовательский институт скорой помощи им. Н.В. Склифосовского \\ Департамента здравоохраненния г. Москвы», г. Москва, Россия
}

\begin{abstract}
Реферат
Актуальность. Качество репозиции отломков при открытом остеосинтезе является одним из важных факторов, определяющих исход лечения. Нередко репозиция и удержание костных отломков представляют собой непростую задачу. Авторами предложен способ репозиции и временного удержания отломков с использованием пластиковых хомутов-стяжек, используемых при электромонтажных работах. Цель - продемонстрировать возможности нового способа интраоперационной репозиции и удержания костных отломков при помощи пластиковых хомутов-стяжек. Материал и методы. Хомуты-стяжки перед операцией подвергают стерилизации в режимах, предназначенных для подготовки полимерных изделий. После выделения отломков осуществляют их репозицию и удержание с помощью зажимов и костодержателей. На этом этапе операции возникает потребность в применении хомутов-стяжек, так как костодержатели препятствуют укладке пластины на кость. Для этого на свободные от костодержателей участки кости в области стыковки отломков накладывают 3-4 пластиковых хомута-стяжки. В тех местах, где к отломку прикрепляются неповрежденная надкостница и мышцы, инструментом формируют узкие поперечные каналы в мягких тканях для обхватывания кости хомутом. Затем свободный конец хомута проводят через его замок и максимально затягивают. После затягивания всех хомутов костодержатели снимают. Наложенные хомуты надежно удерживают костные фрагменты от каких-либо смещений даже при ротации сегмента. Поверх кости с затянутыми хомутами-стяжками укладывают накостный фиксатор. Затем фиксируют пластину к кости винтами. Следует укладывать пластину на кость без сильного прижатия, что позволяет удалять хомуты-стяжки из-под пластины на любом этапе остеосинтеза. Стяжки удаляют, разрезая их скальпелем или перекусывая кусачками, затем пластину закрепляют к кости оставшимися винтами. Заключение. Хомуты-стяжки обладают многими преимуществами: они доступны, дешевы, не теряют своих механических свойств после стерилизации, позволяют надежно удерживать отломки костей во время репозиции, рентгенонегативны. Метод продемонстрировал удобство и надежность.
\end{abstract}

Ключевые слова: накостный остеосинтез, репозиция отломков, хомуты-стяжки.

Источник финансирования: исследование проведено без спонсорской поддержки.

$\mathbb{2}[$ Иванов П.А., Касацкий А.В., Заднепровский Н.Н., Неведров А.Н. Новый способ открытой репозиции и удержания костных отломков с использованием пластиковых хомутов-стяжек. Травматология и ортопедия России. 2021;27(4):93-98. https://doi.org/10.21823/2311-2905-1664.

Cite as: Ivanov P.A., Kasatskiy A.V., Zadneprovskiy N.N., Nevedrov A.V. [A New Method of Intraoperative Reposition and Holding of Bone Fragments with Ty-Raps]. Travmatologiya $i$ ortopediya Rossii [Traumatology and Orthopedics of Russia]. 2021;27(4):93-98. (In Russian). https://doi.org/10.21823/2311-2905-1664.

$\triangle$ Иванов Павел Анатольевич / Pavel A. Ivanov; e-mail: ipamailbox@gmail.com

Рукопись получена: 10.08.2021. Рукопись одобрена: 19.11.2021. Статья опубликована онлайн: 13.12.2021. Submitted: 10.08.2021. Accepted: 19.11.2021. Published Online: 13.12.2021.

(c) Иванов П.А., Касацкий А.В., Заднепровский Н.Н., Неведров А.Н., 2021

(c) Ivanov P.A., Kasatskiy A.V., Zadneprovskiy N.N., Nevedrov A.V., 2021 


\title{
A New Method of Intraoperative Reposition and Holding of Bone Fragments with Ty-Raps
}

\author{
Pavel A. Ivanov, Aleksandr V. Kasatskiy, Nikita N. Zadneprovskiy, Aleksandr V. Nevedrov \\ Sklifosovsky Research Institute of Emergency Medicine, Moscow, Russia
}

\begin{abstract}
Background. The quality of fractures reposition in open osteosynthesis is one of the important factors determining the outcome of treatment. Often, the reposition and fixation of bone fragments is not an easy task. The authors propose a method of reposition and temporary fixation of fragments using plastic ty-raps used in electrical work. The aim of the study is to demonstrate the possibilities of new method of intraoperative reposition and fixation of bone fragments using plastic ty-raps. Materials and Methods. Ty-raps were sterilized before the surgery in the modes intended for the preparation of polymer products. After the fragments were dissected, their reposition and fixation are carried out with the help of clamps and bone clamps. At this stage, there is a need for the use of ty-raps, since the bone clamps prevent the plate from laying on the bone. To do this, 3-4 plastic ty-raps were applied to the areas of bone free from bone clamps in the area of the fragments contact. In those places where an intact periosteum and muscles are attached to the fragment, narrow transverse channels in soft tissues are formed with the instrument to wrap the bone with a ty-rap. Then the free end of the ty-rap is passed through its lock and tightened as much as possible. After tightening all the ty-raps, the bone clamps are removed. The applied tyraps reliably keep the bone fragments from any displacement, even when the segment rotates. A bone plate is placed on the bone surface with tightened ty-raps. Then the plate fixed to the bone with screws. The plate should be placed on the bone without strong pressing, which allows you to remove the ty-raps from under the plate at any stage of osteosynthesis. The ty-raps are removed by cutting them with a scalpel or snacking with wire cutter, then the plate is fixed to the bone with the remaining screws. Conclusion. Ty-raps have many positive properties: they are affordable, cheap, do not lose their mechanical properties after sterilization, allow you to securely hold bone fragments during reposition, X-ray negative. The method has demonstrated convenience and reliability.
\end{abstract}

Keywords: plate fixation, bone fragments reposition, ty-raps.

Funding: no funding or sponsorship was received for this study.

Competing interests: the authors declare that there are no competing interests.

\section{Введение}

Репозиция и удержание костных отломков при открытой репозиции во время операций остеосинтеза представляет собой непростую задачу. Степень восстановления анатомии поврежденной кости - это ключевой фактор, от которого зависит как ранний результат вмешательства, так и исход лечения в целом. Качество репозиции напрямую определяет степень стабильности остеосинтеза, вероятность формирования несращения и развития гнойных осложнений $[1,2,3]$.

Нами предложен и успешно апробирован на практике способ репозиции и временного удержания отломков во время открытого остеосинтеза с помощь пластиковых хомутов-стяжек, используемых при электромонтажных работах. В строительстве и в быту хомуты-стяжки позволяют быстро и качественно закрепить различные детали и элементы конструкций между собой. Простая и надежная конструкция хомутов-стяжек, удобство их монтажа, дешевизна - вот причины, по которым они завоевали заслуженную популярность на производстве и в быту (рис. 1).

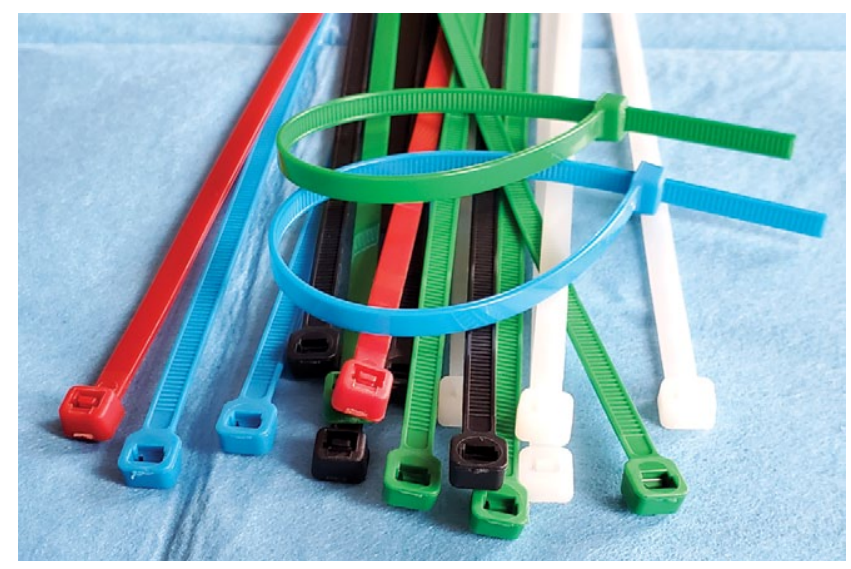

Рис. 1. Пластиковые хомуты-стяжки

Fig. 1. Plastic ty-raps

Изделия из полимеров давно и успешно применяются в хирургической практике (дренажные трубки, канюли, катетеры, грыжевые сетки, вкладыши эндоротезов и т.п.). Возможность стерилизации, нетоксичность материала, высокие потребительские свойства изделий из полимеров сделали 
их очень популярными в медицине. Пластиковые хомуты-стяжки также привлекли внимание медицинских специалистов. Один из примеров их применения приведен в статье наших коллег из Нидерландов, в которой авторы делятся своим опытом успешного использования данной оснастки для дерматотензии при закрытии ран после фасциотомии [4]. Именно эта работа вдохновила нас на разработку представленного сегодня способа.

Цель работы - продемонстрировать возможности нового способа интраоперационной репозиции и удержания костных отломков при помощи пластиковых хомутов-стяжек.

\section{Хирургическая техника}

Хомуты-стяжки перед операцией подвергают стерилизационной обработке в стандартных режимах, предназначенных для подготовки полимерных изделий. Методика применения хомутов-стяжек во время остеосинтеза отличается простотой. После выделения отломков осуществляют их репозицию и удержание с помощью зажимов и костодержателей по обычной методике. Именно на этом этапе операции и возникает потребность в применении разработанного нами способа, так как наложенные на кость костодержатели препятствуют укладке пластины на кость (рис. 2а). Для этого на свободные от костодержателей участки кости в области стыковки отломков накладывают 3-4 пластиковых хомута-стяжки (рис. 2b). В тех местах, где к отломку прикрепляются неповрежденная надкостница и мышцы, инструментом формируют узкие поперечные каналы в мягких тканях для обхватывания кости хомутом. Затем свободный конец хомута проводят через его замок и максимально затягивают. После затягивания всех хомутов костодержатели снимают (рис. 2c).
Наложенные хомуты надежно удерживают костные фрагменты от каких-либо смещений даже при ротации сегмента. Затем поверх кости с затянутыми хомутами-стяжками укладывают накостный фиксатор (рис. 2 d). При необходимости ему придают неподвижность с помощью костодержателя или дополнительных хомутов. После этого начинают фиксировать пластину к кости винтами. Важно исключить сильное зажатие хомута под пластиной. Если пластину укладывают на кость без сильного прижатия, то стяжки будут удаляться из-под пластины без труда на любом этапе остеосинтеза. Если же пластину притягивают к кости костодержателями или кортикальными винтами, то лучше удалять стяжки до этапа вкручивания ближайших к месту перелома винтов, чтобы избежать их плотного зажатия под пластиной. Для дополнительного ослабления придавливания стяжки рядом с хомутом в щель под пластину можно ввести малый элеватор или крючок малого ретрактора Хомана и отдавить фиксатор от кости. Стяжки удаляют, разрезая их скальпелем или перекусывая кусачками (рис. 2 е). После этого пластину закрепляют к кости оставшимися винтами.

Перед закрытием раны следует провести подсчет фрагментов хомутов-стяжек, чтобы исключить их оставление в ране. Лучше использовать изделия из яркого цветного пластика, что помогает идентифицировать их в операционном поле.

Уникальные свойства хомутов-стяжек позволяют использовать их не только для удержания, но и для репозиции переломов с длинными костными осколками. Для этого хомуты накладывают на отломки на разных уровнях, но затягивают их неполностью. Затем в ходе репозиции их последовательно дотягивают, тем самым поэтапно помогая сближать и удерживать отломки в правильном положении относительно друг друга.
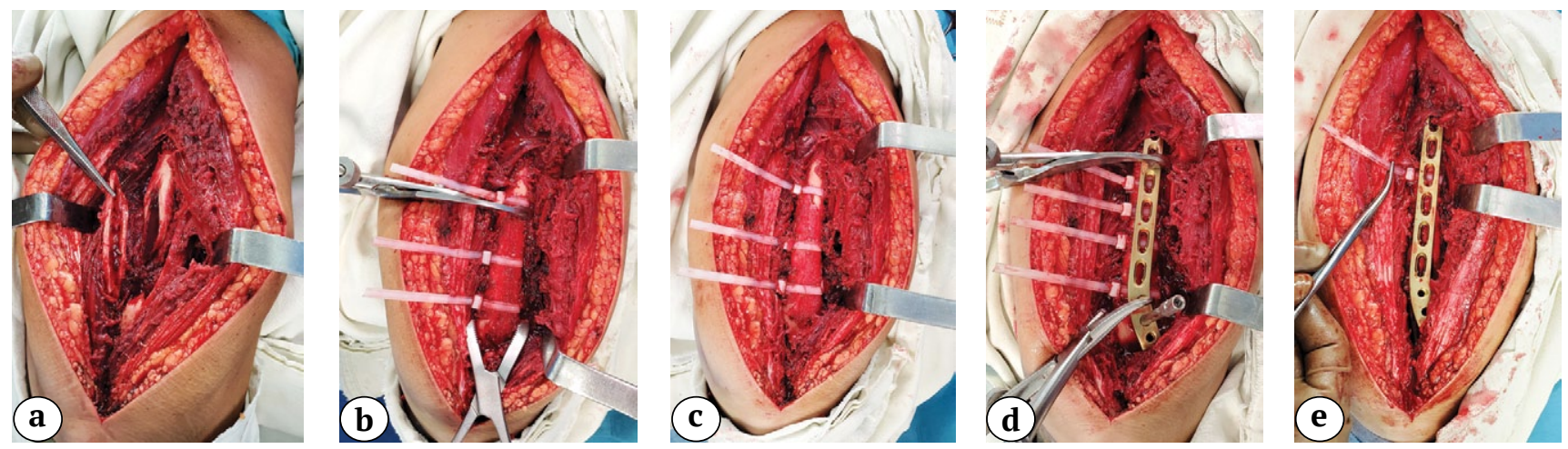

Рис. 2. Этапы использования хомутов-стяжек для удержания костных отломков:

$\mathrm{a}$ - положение отломков до начала репозиции; $\mathrm{b}$ - после наложения костодержателей и хомутов-стяжек;

c - после снятия костодержателей; d - после наложения пластины; е - удаление хомутов-стяжек

Fig. 2. Stages of using ty-raps to hold bone fragments:

$\mathrm{a}-$ the position of the fragments before the start of the reposition; $b$ - after applying the bone clamps and ty-raps; $\mathrm{c}-$ after removing the bone clamps; $\mathrm{d}$ - after applying the plate; $\mathrm{e}-$ removing the ty-raps 


\section{Обсуждение}

Предложенный нами способ репозиции привлекателен благодаря доступности, эффективности и простоте исполнения. Хомуты-стяжки дешевы и доступны, продаются в большом ассортименте в строительных, компьютерных и хозяйственных магазинах (синонимы - пластиковая стяжка, кабельная стяжка, нейлоновая стяжка, стяжка-хомут, хомут пластиковый, хомут нейлоновый, стяжка полиамидная, хомут полиамидный, хомут кабельный, стяжка KCC, хомут KSS и так далее). Они отличаются по виду и свойствам материла, размеру, цвету, профилю, конструкции замка, возможности размыкания и повторного затягивания и т.п. Данные изделия не меняют своих физических свойств при любом из широко применяемых способов медицинской стерилизации.

Предложенный нами способ схож с классическим способом наложения проволочного серкляжа, но имеет очевидные преимущества. Он проще, дешевле, быстрее. Кроме этого, полимерный хомут-стяжка намного бережнее обхватывает кость и надкостницу, чем металлическая проволока [5]. Это обусловлено не только материалом, из которого они изготовлены. Стяжка обычно имеет форму ленты и, в отличие от проволоки, распределяет давление обхвата на большую площадь и меньше повреждает подлежащие ткани. Это свойство способа дает существенное преимущество при операциях у пожилых людей с истончением кортикального слоя и повышенной хрупкостью кости [6]. При использовании костодержателя его губки давят лишь на две точки окружности в месте контакта инструмента и кости. При сильном зажатии может происходить раскалывание отломков и усугубление нестабильности. Метод с использованием хомута-стяжки не содержит таких рисков - нагрузка давления на кость равномерно распределяется по всей длине окружности обхвата.

Предложенный способ имеет очевидные преимущества перед способами с наложением костодержателей. Бранши костодержателя нужно накладывать только в определенной плоскости

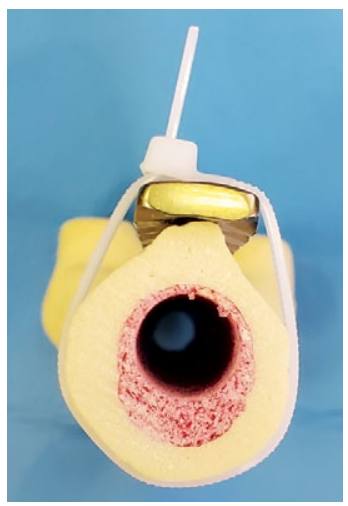

Рис. 3. Временная фиксация пластины на гребне кости

Fig. 3. Temporary fixation of the plate on the ridge of the bone по отношению к плоскости соприкосновения отломков для их компрессии. При ошибочном выборе плоскости сдавления отломков возникает смещение отломков. Нередко расположить костодержатель в оптимальной позиции от плоскости перелома бывает затруднительно. Так, при придавливании пластины к кости костодержателем, особенно над костными гребнями или костью с поперечным сечением овальной формы, пластина стремится соскользнуть с кости ввиду несоответствия контура последней и профиля фиксатора. Разработанный нами способ лишен данного недостатка, так как хомут равномерно охватывает кость и фиксатор и удерживает пластину с боковых сторон от соскальзывания (рис. 3). Поэтому при многооскольчатых переломах хомуты-стяжки являются практически безальтернативным инструментом при репозиции отломков.

Способ позволяет сближать отломки не только в направлении, перпендикулярном оси кости. Нами используется прием сдавления в диагональном направлении при помощи упора о спицу (рис. 4). Для этого после сопоставления отломков через концы в косом направлении проводят спицу. После этого хомут проводят по разные стороны от спицы и затягивают. Таким образом, он надежно располагается в заданном косом направлении по отношению к оси кости и перпендикулярно плоскости стыковки косых концов отломков.

Хомуты-стяжки изготовлены из рентгенопрозрачного материала, что наделяет их уникальными свойствами по сравнению с любым другим металлическим хирургическим инструментом. Нередко при рентгеноскопии во время операции металлические костодержатели и зажимы закрывают важные участки, усложняя контроль качества репозиции (рис. $5 \mathrm{a}, \mathrm{b}$ ). Пластиковые устройства не создают в этом отношении препятствий - во время операции они не мешают визуализировать кость на любом участке (рис. 5 с). Качество удержания отломков во время остеосинтеза подтверждается послеоперационными рентгенограммами (рис. $5 \mathrm{~d}, \mathrm{e})$.

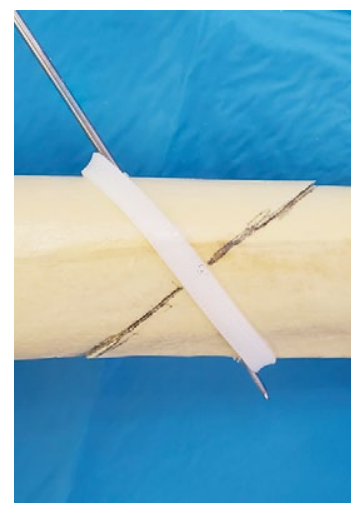

Рис. 4. Временная фиксация косого перелома с помощью спицы и хомута-стяжки

Fig. 4. Temporary fixation of an oblique fracture with a wire and a ty-rap 

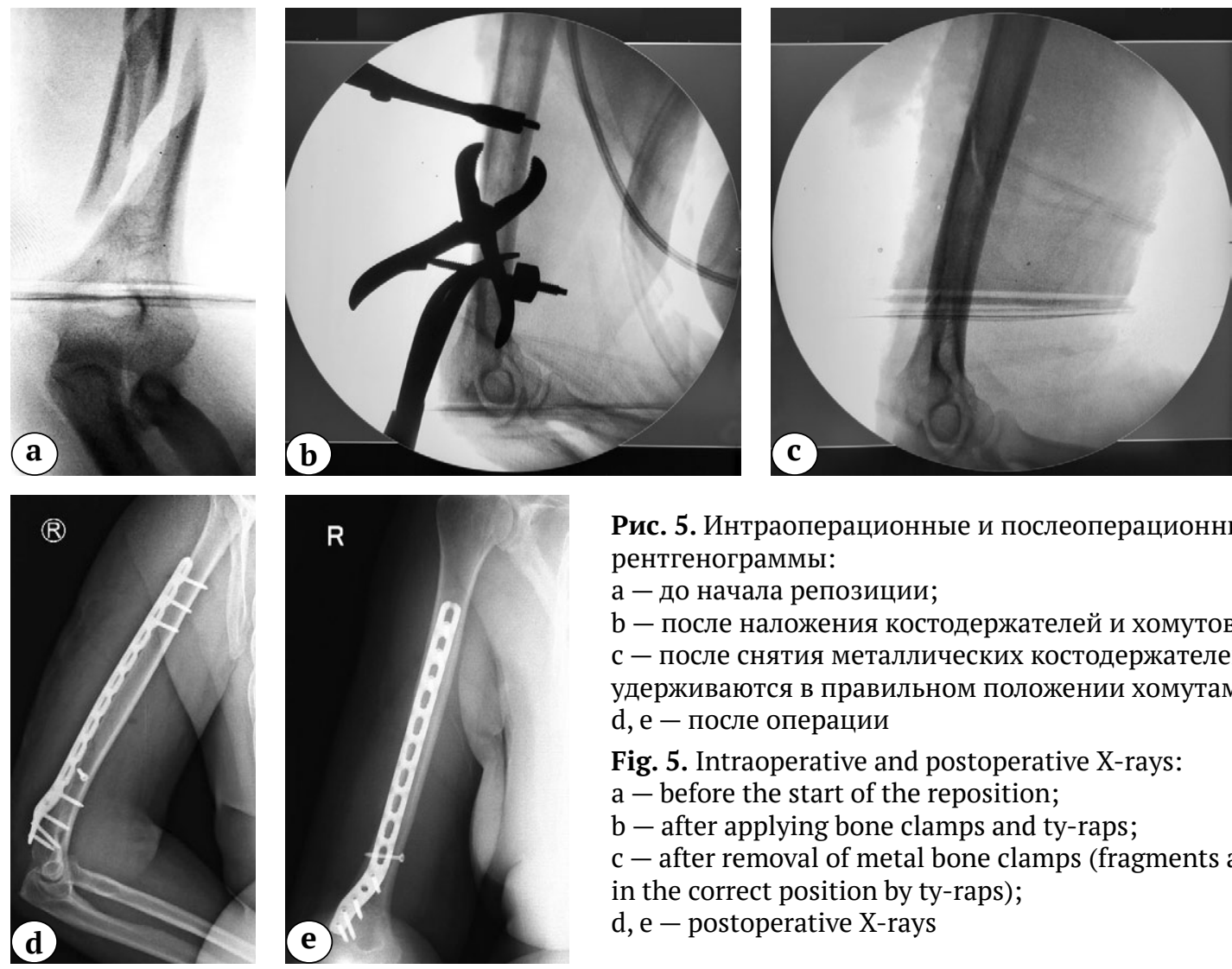

Рис. 5. Интраоперационные и послеоперационные рентгенограммы:

a - до начала репозиции;

$\mathrm{b}$ - после наложения костодержателей и хомутов-стяжек;

c - после снятия металлических костодержателей (отломки удерживаются в правильном положении хомутами-стяжками); $\mathrm{d}, \mathrm{e}$ - после операции

Fig. 5. Intraoperative and postoperative X-rays:

$\mathrm{a}$ - before the start of the reposition;

$\mathrm{b}-$ after applying bone clamps and ty-raps;

c - after removal of metal bone clamps (fragments are held in the correct position by ty-raps);

$\mathrm{d}, \mathrm{e}-$ postoperative X-rays

\section{Заключение}

Предложенный нами способ репозиции и удержания костных отломков с помощью хомутов-стяжек во время открытого остеосинтеза отличается надежностью, удобством и доступностью для применения. Он помогает удерживать отломки в правильном положении без риска дополнительного раскалывания кости и не создает препятствий при итраоперационной рентгеноскопии. Для уточнения степени эффективности предложенного способа необходимо проведение дополнительных исследований.

\section{Этическая экспертиза}

Протокол применения предложенного нами способа был одобрен локальным комитетом по биомедицинской этике ГБУЗ «Научноисследовательский институт скорой помощи им. Н.В. Склифосовского Департамента здравоохранения г. Москвы» (протокол №7-17 от 18 сентября 2017 г.).

\section{Литература [References]}

1. Shapiro F. Cortical bone repair. The relationship of the lacunar-canalicular system and intercellular gap junctions to the repair process. J Bone Joint Surg Am. 1988;70(7):1067-1081.

2. Perren S.M. Evolution of the internal fixation of long bone fractures. The scientific basis of biological internal fixation: choosing a new balance between stability and biology. I Bone Joint Surg Br. 2002;84(8):1093-1110. doi: 10.1302/0301-620x.84b8.13752.

3. Попов В.П., Здрелько В.П., Трухачев И.Г., Попов А.В. Осложнения при накостном остеосинтезе у больных с переломами длинных трубчатых костей. Гений ортопедии. 2014;(2):5-9.

Popov V.P., Zdrelko V.P., Trukhachev I.G., Popov A.V. [Complications of extramedullary osteosynthesis in patients with long bone fractures]. Genij Ortopedii. 2014;(2):5-9. (In Russian).

4. Govaert G.A., van Helden S. Ty-raps in trauma: a novel closing technique of extremity fasciotomy wounds. J Trauma. 2010;69(4):972-975. doi: 10.1097/TA.0b013e3181f2d9d3.

5. Westberg S.E., Acklin Y.P., Hoxha S., Ayranci C., Adeeb S., Bouliane M. Is suture comparable to wire for cerclage fixation? A biomechanical analysis. Shoulder Elbow. 2019;11(3):225-232. doi: $10.1177 / 1758573217735323$.

6. Seeman E., Delmas P.D. Bone quality - the material and structural basis of bone strength and fragility. $N$ Engl $J$ Med. 2006;354(21):2250-2261. doi: 10.1056/NEJMra053077. 


\section{СВЕДЕНИЯ ОБ АВТОРАХ:}

Иванов Павел Анатольевич - д-р мед. наук, заведующий научным отделением сочетанной и множественной травмы, ГБУЗ «Научно-исследовательский институт скорой помощи им. Н.В. Склифосовского Департамента здравоохраненния г. Москвы», г. Москва, Россия e-mail: ipamailbox@gmail.com

https://orcid.org/0000-0002-2954-6985

Касацкий Александр Викторович - врач травматологического отделения, ГБУЗ «Научно-исследовательский институт скорой помощи им. Н.В. Склифосовского Департамента здравоохраненния г. Москвы», г. Москва, Россия

e-mail: avkkasatsky@mail.ru

https://orcid.org/0000-0002-9779-530X

Заднепровский Никита Николаевич - канд. мед. наук, научный сотрудник отделения сочетанной и множественной травмы, ГБУЗ «Научно-исследовательский институт скорой помощи им. Н.В. Склифосовского Департамента здравоохраненния г. Москвы», г. Москва, Россия

e-mail: zacuta2011@gmail.com

https://orcid.org/0000-0002-4432-9022

Неведров Александр Валерьевич - канд. мед. наук, врач травматологического отделения, ГБУЗ «Научноисследовательский институт скорой помощи им. Н.В. Склифосовского Департамента здравоохраненния г. Москвы», г. Москва, Россия

e-mail: alexnev1985@yandex.ru

https://orcid.org/0000-0002-1560-6000

\section{Заявленный вклад авторов}

Иванов П.А. - дизайн исследования.

Касаикий А.В. - дизайн исследования.

Заднепровский Н.Н. - написание текста статьи.

Неведров А.В. - обзор литературы.

Все авторы прочли и одобрили финальную версию рукописи статьи. Все авторы согласны нести ответственность за все аспекты работы, чтобы обеспечить надлежащее рассмотрение и решение всех возможных вопросов, связанных с корректностью и надежностью любой части работы.

Конфликт интересов

Авторы заявляют об отсутствии конфликта интересов.

\section{AUTHORS' INFORMATION:}

Pavel A. Ivanov - Dr. Sci. (Med.), Sklifosovsky Research Institute of Emergency Medicine, Moscow, Russia e-mail: ipamailbox@gmail.com https://orcid.org/0000-0002-2954-6985

Aleksandr V. Kasatskiy - Sklifosovsky Research Institute of Emergency Medicine, Moscow, Russia e-mail:av kasatsky@mail.ru https://orcid.org/0000-0002-9779-530X

Nikita N. Zadneprovskiy - Cand. Sci. (Med.), Sklifosovsky Research Institute of Emergency Medicine, Moscow, Russia e-mail: zacuta2011@gmail.com https://orcid.org/0000-0002-4432-9022

Aleksandr V. Nevedrov - Cand. Sci. (Med.), Sklifosovsky Research Institute of Emergency Medicine, Moscow, Russia e-mail: alexnev1985@yandex.ru https://orcid.org/0000-0002-1560-6000 